\title{
Swimming turn performance: the distinguishing factor in 1500m World championship freestyle races?
}

Marek Polach ( $\sim$ marek.polach01@upol.cz)

Palacký University, Olomouc https://orcid.org/0000-0002-9531-5130

\section{Dan Thiel}

Charles University Faculty of Physical Education and Sport: Univerzita Karlova Fakulta telesne vychovy a sportu

\section{Jan Kreník}

Czech Swimming Federation

\section{Dennis-Peter Born}

Swiss Federal Institute of Sport Magglingen: Eidgenossische Hochschule fur Sport Magglingen

\section{Research note}

Keywords: elite athletes, front crawl, performance analysis, start

Posted Date: March 2nd, 2021

DOI: https://doi.org/10.21203/rs.3.rs-275015/v1

License: (c) (i) This work is licensed under a Creative Commons Attribution 4.0 International License. Read Full License 


\section{Abstract \\ Objective}

Turn sections represent the second largest part of total race time in $1500 \mathrm{~m}$ freestyle races and may substantially affect race results. Therefore, the aim of the study was to investigate individual race strategies and compare the effect of start, swim, and turn performances between short-course and longcourse races. Video footages were collected from all male finalists at the 2018 short- $(n=8$, age $22.8 \pm 2.4$ years, FINA points $953 \pm 27$ ) and 2019 long-course World swimming championships ( $n=8$, age $23.3 \pm 2.2$ years, FINA points $951 \pm 23$ ) for subsequently analysis of start, turn, and swim performance.

\section{Results}

The larger number of turns in short-course races resulted in significantly faster race times $(p<0.001)$, but slower mean turn times compared to long-course races $(p<0.001)$. Total race time closely correlated with swim and turn but not start section time in short- $(r \geq 0.76, p \leq 0.030)$ and long-course races $(r \geq 0.96, p<$ 0.001). Analysis of individual race strategies showed that turn performance affected race results in 9 of the 16 world-best $1500 \mathrm{~m}$ swimmers and improved medal standing of $1 \mathrm{st}$, 3rd, and 4th ranked short- as well as 1 st and 2 nd ranked long-course finalist. Coaches, athletes, and performance analysts may carefully consider the importance of turn performance additionally to free-swimming skills.

\section{Introduction}

Performance analysis has become routine procedure in high-performance sports, in order to evaluate the training process, discover potentials, and investigate key performance indicators [1, 2]. As pool swimming is affected by little environmental factors, swimming performance can be assessed based on real race scenarios with no equipment interfering with the swimmer's movement pattern [3, 4]. Performance analysts commonly divide swim races into several sections. The start section involves the first meters of the race and includes the jump from the starting block, flight phase, underwater phase, and transition to full-stroke swimming [5, 6]. Contribution of start performance in $50 \mathrm{~m}$ events was $26.1 \%$ [7] but continuously decreased for $100 \mathrm{~m}$ and $200 \mathrm{~m}$ races $[8,9]$ and may be of minor importance for $1500 \mathrm{~m}$ freestyle $[8,10]$. Here, turns that are used for directional change and to reaccelerate the swimmer by pushing of the pool wall at the beginning of each lap may substantially affect the race result [11]. The turn sections are commonly analyzed from $5 \mathrm{~m}$ before wall contact until resurfacing after the underwater phase, which varies in its length depending on the race distance $[12,13]$. Distance between the start and turns determine swim section $[3,8,14]$.

While parameters related to free-swimming have been extensively investigated [1, 15-17], turns represent $19.69 \pm 0.24 \%$ [8] and $36.87 \pm 0.61 \%$ [18] of total race time in $100 \mathrm{~m}$ and $1500 \mathrm{~m}$ long-course freestyle races, respectively. Significant performance variations were attributed to turn parameters, i.e. $5 \mathrm{~m}$ in (time before wall contact), breakout time, breakout distance, $15 \mathrm{~m}$ out (time after wall contact) $[8,10,18]$. 
However, in these particular studies, turn sections were based on FINA rules that allow an underwater phase up to the $15 \mathrm{~m}$ mark [19]. As mean breakout distance was $5.48 \pm 0.87 \mathrm{~m}$ in these $1500 \mathrm{~m}$ races [18], free-swimming skills may have large affected turn performance. Therefore, previous studies suggested to isolate the turn and swim sections $[12,13]$ with particular attention to the last $5 \mathrm{~m}$ before and initial $5 \mathrm{~m}$ after wall contact $[20,21]$.

In long-course races (50 $\mathrm{m}$ pool length), the effect of turn performance on race results increased with race distance, hence number of turns involved $[8-10,18]$. As the number of turns is twice as high in $1500 \mathrm{~m}$ short-course races ( $25 \mathrm{~m}$ pool length), turn performance may show an even larger effect on race results. While analysis of world-class athletes provides unique insights into human's highest possible performance, such analyses are naturally limited by a small number of subjects [22, 23]. Hence, performance at World championship level should be investigated based on individualized responses and case reports in addition to the assessment of mean values [24-26]. Therefore, the aim of the study was to investigate individual race strategies of World championship finalists and compare the effect of start, swim, and turn performances on results of $1500 \mathrm{~m}$ freestyle events between short-course and long-course races.

\section{Materials And Methods Participants}

Video footages were collected from all 8 male finalists of the $1500 \mathrm{~m}$ freestyle events at the Hangzhou 2018 (age $22.8 \pm 2.4$ years, FINA points $953 \pm 27$ ) short-course ( $25 \mathrm{~m}$ pool length) and Gwangju 2019 (age $23.3 \pm 2.2$ years, FINA points $951 \pm 23$ ) long-course ( $50 \mathrm{~m}$ pool length) World championships for subsequent analyses of start, turn, and swim sections. All participants of the FINA World swimming championships provided written informed consent to the organizer that all video material collected during competition can be used for television broadcasting and race analyses by the participating nations. All data were anonymized before the analyses. The Institutional review board of the Palacký University of Olomouc approved the procedure and that the present study is in accordance with the Declaration of Helsinki (Registration-Number: 77/2020).

\section{Data collection}

For the short-course World championships, a camera (Canon XA35, Canon Inc., Tokio, Japan) was positioned on top of the stands $30 \mathrm{~m}$ above water level and about $100 \mathrm{~m}$ from the side of the pool. The camera was placed perpendicular to the direction of swimming and exactly in the middle of the pool (12.5 $\mathrm{m}$ apart from both pool ends). The camera zoom was set before the races to assure clear vision across the entire pool. To ensure same conditions for the long-course World championships (50 m pool length), two cameras of the same type used before, were positioned $12.5 \mathrm{~m}$ apart from both ends of the pool. Cameras were synchronized via wireless LAN connection and recorded half to the pool each. Videos footages were recorded as mp4 format with 50 frames-per-seconds and an image qualify of $1920 \times 1080$ full HD. 


\section{Data analysis}

Split times for start, swim, and turn sections were analysed using Dartfish (Team pro Data 9, Dartfish, Fribourg, Switzerland). The light flash of the timing system that was synchronized to the starting signal was used to synchronize video footages for the race analysis. As described previously [27], references markers at on the lane ropes at $5 \mathrm{~m}, 20 \mathrm{~m}$, and $45 \mathrm{~m}$, were used for the distance measures. Before the race, accuracy of the markers was checked using a measuring tape. Race results were obtained from the official electronical timing system (Omega Timing, Biel/Bienne, Switzerland).

Based on the mean breakout distances of $10.69 \pm 1.18 \mathrm{~m}$ and $10.11 \pm 1.25 \mathrm{~m}$ for short- and long-course races, respectively, start section was determined by the time from the starting signal until top of the swimmer's head passed the $10 \mathrm{~m}$ mark. Based on previously reported breakout distances between $4.64 \pm$ $0.23 \mathrm{~m}$ and $5.48 \pm 0.87 \mathrm{~m}$ in $1500 \mathrm{~m}$ freestyle races $[18,28]$, turn sections were analysed from $5 \mathrm{~m}$ before until $5 \mathrm{~m}$ after wall contact. Swimmer's head passing the $5 \mathrm{~m}$ marks were used as reference points. Race sections beyond start and turn section determined the swim section.

\section{Statistical analysis}

The data are presented in mean \pm standard deviation (SD). After verification of normality with ShapiroWilks test, Pearson's correlation coefficient was used to assess relationship between split times and ranking in all race sections. Differences of mean turn times at the short-course and long-course World championships were determined using a $T$-test for independent samples with $p<0.05$ indicating statistical significance. To investigate accuracy of the race analyses, fifty percent of all races were analysed by another experienced race analysts. Inter-rater reliability was assess using Intraclasscorrelation coefficient (ICC) between the repeated measures and showed an ICC of 0.988-0.989 and 0.991-0.992 for short-course and long-course World championships, respectively. Statistical analysis was performed using the STATISTICA software version 13.4.0.14. (StatSoft Inc., Tulsa, USA).

\section{Results}

The times for start, swim, and turn sections are presented in Table 1 (mean \pm standard deviation) for shortcourse and long-course $1500 \mathrm{~m}$ races. Short-course races showed a significantly faster total race time $(p<0.001)$ compared to long-course races. Additionally, in short-course races, swimmers spent significantly less time in the swim $(64.52 \%$ vs. $83.04 \%, p<0.001)$ and more time in the turn sections $(35.04 \%$ vs. $16.53 \%, p<0.001)$ compared to long-course races, respectively. However, mean turn time was significantly $(p<0.001)$ faster for long-course compared to short-course races $(5.07 \pm 0.18$ vs. $5.14 \pm 0.10 \mathrm{~s})$.

Correlation analysis revealed close correlations between the final ranking with swim and turn section ranking in both, short- $(r \geq 0.74, p \leq 0.037)$ and long-course races $(r=0.93, p<0.001)$. Additionally, total race time correlated with swim and turn section time in short- $(r \geq 0.76, p \leq 0.030)$ and long-course races $(r \geq 0.96, p<0.001)$. Start performance was not related to final ranking or total race time. 
Figure 1 illustrates the individual response of the swimmer's swim and turn performance on final ranking. Turn performance affected final ranking in 9 out of 16 World championship finalists. In particular, for the highest ranked swimmers, turn performance improved medal standing, i.e. $1^{\text {st }}, 3^{\text {rd }}$, and $4^{\text {th }}$ ranked shortcourse finalist as well as $1^{\text {st }}$ and $2^{\text {nd }}$ ranked long-course finalist. For instance, in short-course races, the swimmer ranked $2^{\text {nd }}(545.35 \mathrm{~s})$ swam $4.71 \mathrm{~s}$ faster than the winner of the race $(550.06 \mathrm{~s})$ but lost $5.18 \mathrm{~s}$ in the turn sections. Moreover, swimmer ranked $3^{\text {rd }}$ only showed the $6^{\text {th }}$ fastest swimming time. However, this swimmer gained up to $14.9 \mathrm{~s}$ due to the turns and outperformed the $4^{\text {th }}, 5^{\text {th }}$, and $6^{\text {th }}$ ranked swimmers with second fastest total turn time. In long-course races, swimmer ranked $3^{\text {rd }}$ swam 1.69s and $1.86 \mathrm{~s}$ faster than the $1^{\text {st }}$ and $2^{\text {nd }}$ ranked swimmer. However, final ranking was determined by faster turn times for $1^{\text {st }}(3.56 \mathrm{~s})$ and $2^{\text {nd }}(2.72 \mathrm{~s})$ compared to $3^{\text {rd }}$ ranked swimmers.

\section{Discussion}

The aim of the study was to investigate individual race strategies of World championship finalists and compare the effect of start, swim, and turn performances on results of $1500 \mathrm{~m}$ freestyle events between short-course and long-course races. The larger number of turns in short-course races resulted in faster race times, but slower mean turn times compared to long-course races. The race result closely correlated with swim and turn section time in both, short- and long-course races. Analysis of individual race strategies showed that turn performance affected final ranking in 9 out of 16 World championship finalists and improved ranking for the $1^{\text {st }}, 3^{\text {rd }}$, and $4^{\text {th }}$ short-and $1^{\text {st }}$ and $2^{\text {nd }}$ long-course finalist.

The present study showed importance of turn performance in $1500 \mathrm{~m}$ freestyle short- and long-course races. The push-off from the pool wall and subsequent underwater phase with application of undulating kicking technique accelerates swimmer above free-swimming speed [29]. Swimmers aim to maximize length of the underwater phase, as drag forces are lower under water than at its surface [30]. However, excess breath holding increases anaerobic demand and may interfere with swimmers free-swimming abilities [31]. Therefore, with increasing race distance, swimmers successively reduce length of underwater phase down to $4.64 \pm 0.23 \mathrm{~m}$ in the $1500 \mathrm{~m}$ freestyle [28] While long-distance swimmers apply rather slow and energy saving leg kicking [32], push-off from the pool wall and undulating kicking during the underwater phase place a high demand on the leg muscles [11]. Future research needs to investigate whether length of the underwater phase and conditioning of leg muscles may provide potential for future performance developments in long-distance swimmers.

In the present study, race times were significantly faster in short- compared to long-course races probably due to twice the number of turns involved, hence repeated velocity gains from wall push-off [29,33]. However, mean turn performance was slower in short-course races. The high demand for leg muscles $[11,32]$ and repeated breath holding during the underwater phase [31] may have resulted in more careful pacing and energy conserving turns. The question arises whether the in average $0.07 \mathrm{~s}$ faster turn times seen in long-course races could be applied in $25 \mathrm{~m}$ pool competition, hence short-course races. With 30 additional turns this would add up to a performance gain of 2.03s and beat the current world record [34] 
by 0.95 and $0.22 \mathrm{~s}$ for the $1^{\text {st }}$ and $2^{\text {nd }}$ ranked swimmer of the recent 2018 World short-course swimming championships. Although, multiple variables interact in a $1500 \mathrm{~m}$ freestyle race, these findings show the potential for future swimming performance and that human in-water locomotion may has not yet found its limit [35].

\section{Conclusion}

The present study showed that turn performance could be the distinguishing factor in Worldchampionship $1500 \mathrm{~m}$ freestyle races. Analysis of individual race strategies revealed that turn performance affected final ranking in 9 of the 16 world-best short- and long-course swimmers. Coaches, athletes, and performance analysts should carefully consider the importance of turn performance in addition to free-swimming skills.

\section{Limitations}

The present study is the first analysing individual race strategies based on start, swim, and turn section times in $1500 \mathrm{~m}$ freestyle finalists at short- and long-course World championships. Due to low number of subjects available when analysing world-class performance, results cannot be translated to a general population of competitive swimmers. Further studies need to verify these findings based on data collections across finalists of multiple World championships. Additionally, individualized distances measurements of underwater phase and breakout distances after the turn would allow further insights and a detailed analysis of turn strategies [12].

\section{Declarations}

\section{Ethics approval and consent to participate}

All participants of the FINA World swimming championships provided written informed consent to the organizer that all video material collected during competition can be used for television broadcasting and race analyses by the participating nations. All data were anonymized before the analyses. The Institutional review board of the Palacký University of Olomouc approved the procedure and that the present study is in accordance with the Declaration of Helsinki (Registration-Number: 77/2020).

\section{Consent for publication}

Not applicable.

\section{Availability of data and material}

All data can be requested at the corresponding author at any time. 


\section{Competing interests}

There are no competing interests

\section{Funding}

There were no specific grants of funding for the present study.

\section{Author's contributions}

Development of study design (MP, DT, JK, DPB); data collection at Hangzhou short-course championships (DT and JK), data collection at Gwangju long-course championships (MP and DPB); data analysis (MP, $\mathrm{DT}, \mathrm{JK}, \mathrm{DPB}$ ); data interpretation (MP, DT, JK, DPB); preparation of the manuscript (MP, DT, JK, DPB). All authors read and approved the final version of the manuscript.

\section{Acknowledgements}

The authors thank the Czech and Swiss swimming federations for the opportunity to take part in both competitions. Moreover, we want to thank Dominik Vavrečka and Jakub Březina for their help with the data analysis and Miroslav Hanáček for his valuable consultation and advice.

\section{References}

1. Hellard P, Dekerle J, Avalos M, Caudal N, Knopp M, Hausswirth C. Kinematic measures and stroke rate variability in elite female 200-m swimmers in the four swimming techniques: Athens 2004 Olympic semi- finalists and French National 2004 Championship semi-finalists. J Sports Sci. 2008;26(1):35-46.

2. Lyons K. Performance Analysis in applied contexts. Int J Perform Anal Sport. 2005;5(3):155-162.

3. Smith DJ, Norris SR, Hogg JM. Performance evaluation of swimmers scientific tools. Sports Med. 2002;32(9):539-554.

4. O'Donoghue P. The use of feedback videos in sport. Int J Perform Anal Sport. 2006;6(2):1-14.

5. Vantorre J, Seifert L, Fernandes R, Vilas-boas JP, Chollet D. Kinematical profiling of the front crawl start. Int J Sports Med. 2010;31(1):16-21.

6. Tor E, Pease D, Ball KA. Characteristics of an elite swimming start. In Biomechanics and Medicine in Swimming Conference. 2014;1:257-263

7. Cossor JM, Mason BR. Swim start performances at the Sydney 2000 Olympic Games. In Biomech Symp. 2001;Univ San Fr. 2001 
8. Morais JE, Marinho DA, Arellano R, Barbosa TM. Start and turn performances of elite sprinters at the 2016 European Championships in swimming. Sport Biomech. 2019;18(1):100-114.

9. Marinho DA, Barbosa TM, Neiva HP, Silva AJ, Morais JE. Comparison of the start, turn and finish performance of elite swimmers in $100 \mathrm{~m}$ and $200 \mathrm{~m}$ races. J Sport Sci Med. 2020;19(2):397-407.

10. Morais JE, Barbosa TM, Neiva HP, Marinho DA. Stability of pace and turn parameters of elite longdistance swimmers. Hum Mov Sci. 2019;63:108-119.

11. Nicol E, Ball K, Tor E. The biomechanics of freestyle and butterfly turn technique in elite swimmers. Sport Biomech. 2019;0(0):1-14.

12. Veiga S, Cala A, Mallo J, Navarro E. A new procedure for race analysis in swimming based on individual distance measurements. J Sports Sci. 2013;31(2):159-165.

13. Silveira GA, Araujo LG, Freitas EDS, Schütz GR, de Souza TG, Pereira SM, et al. Proposal for standardization of the distance for analysis of freestyle flip-turn performance. Braz J Kinantrop Hum Perform. 2011;13(3):177-182.

14. Kjendlie P, Stallman RK. The temporal distribution of race elements in elite swimmers. Port J Sport Sci. 2014; 6(2):54-56.

15. Arellano R, Brown P, Cappaert J, Nelson RC. Analysis of 50-, 100-, and 200-m freestyle swimmers at the 1992 Olympic Games. J Appl Biomech. 1994;10(2):189-199.

16. Craig $A B$, Pendergast $D R$. Relationships of stroke rate, distance per stroke, and velocity in competitive swimming. Med Sci Sport. 1979;11(3):278-283.

17. Pai YC, Hay JG, Wilson BD. Stroking techniques of elite swimmers. J Sports Sci. 1984;2(3):225-239.

18. Morais JE, Barbosa TM, Forte P, Bragada JA, Flávio A, Castro DS, et al. Stability analysis and prediction of pacing in elite 1500 m freestyle male swimmers. Sport Biomech. 2020;0(0):1-18.

19. FINA. Swimming and facilities rules 2017-2021 [Internet]. Lausanne: FINA; 2020[Valid as of 21 September 2017]. Available from: https://www.fina.org/sites/default/files/2017_2021_swimming_12092017_ok_0.pdf

20. Blanksby B, Skender S, Elliott B, Mcelroy K, Landers G, Mcelroy K, et al. Swimming: An analysis of the rollover backstroke turn by age-group swimmers. Sport Biomech. 2004;3(1):1-14.

21. Cossor JM, Blanksby BA, Elliott BC. The influence of plyometric training on the freestyle tumble turn. J Sci Med Sport. 1999;2(2)106-16.

22. Barbosa AC, Valadão PF, Wilke CF, Martins F de S, Silva DCP, Volkers SA, et al. The road to 21 seconds: A case report of a 2016 Olympic swimming sprinter. Int J Sport Sci Coach. 2019;14(3):393405.

23. Trappe S, Luden N, Minchev K, Raue U, Jemiolo B, Trappe TA. Skeletal muscle signature of a champion sprint runner. J Appl Physiol. 2015;118(12):1460-1466.

24. Rakovic E, Paulsen G, Helland C, Eriksrud O, Haugen T. The effect of individualised sprint training in elite female team sport athletes: A pilot study. J Sports Sci. 2018;36(24):2802-2808. 
25. Friedmann B, Frese F, Menold E, Kauper F, Jost J, Bärtsch P. Individual variation in the erythropoietic response to altitude training in elite junior swimmers. Br J Sports Med. 2005;39(3):148-153.

26. Haugen T, Seiler S, Sandbakk $\varnothing$, Tønnessen E. The Training and Development of Elite Sprint Performance: an Integration of Scientific and Best Practice Literature. Sport Med - Open. 2019;5(1):44.

27. Veiga S, Roig A. Effect of the starting and turning performances on the subsequent swimming parameters of elite swimmers. Sport Biomech. 2017;16(1):34-44.

28. Chow C, Hay JG, Wilson BD, Imel C. Turning techniques of elite swimmers. 1984;2(3):37-41.

29. Veiga S, Roig A. Underwater and surface strategies of $200 \mathrm{~m}$ world level swimmers. J Sports Sci. 2016;34(8):766-771.

30. Tor E, Pease DL, Ball KA. How does drag affect the underwater phase of a swimming start?. J Appl Biomech. 2015;31(1)8-12.

31. Rodríguez-Zamora L, Engan HK, Lodin-Sundström A, Schagatay F, Iglesias X, Rodríguez FA, et al. Blood lactate accumulation during competitive freediving and synchronized swimming. Undersea Hyperb Med. 2018;45(1):55-63.

32. Kobayashi Yamakawa K, Shimojo H, Takagi H, Tsubakimoto S, Sengoku Y. Effect of increased kick frequency on propelling efficiency and muscular co-activation during underwater dolphin kick. Hum Mov Sci. 2017;54:276-286.

33. Keskinen OP, Keskinen KL, Mero AA. Effect of pool length on blood lactate, heart rate, and velocity in swimming. Int J Sports Med. 2007;28(05)407-413.

34. FINA [Internet]. Lausanne: FINA;2020. fina-rankings/records;2018-2020. Available from: http://www.fina.org/fina-rankings/filter/records

35. Sandbakk $\varnothing$, Solli GS, Christer Holmberg H. Sex differences in world record performance: the influence of sport discipline and competition duration. Int J Sports Physiol Perform. 2018;13(1):2-8.

\section{Tables}


Table 1 - Descriptive data with mean \pm standard deviation (SD) for section time analysis.

Short-course World championships Long-course World championships

$25 \mathrm{~m}$ pool length - Hangzhou 2018 50m pool length - Gwangju 2019

Mean \pm SD $\quad 95 \% \mathrm{Cl} \quad$ Mean \pm SD $\quad 95 \% \mathrm{Cl}$

\begin{tabular}{|c|c|}
\hline $\begin{array}{l}\text { lower } \\
\text { bound }\end{array}$ & $\begin{array}{l}\text { upper } \\
\text { bound }\end{array}$ \\
\hline
\end{tabular}

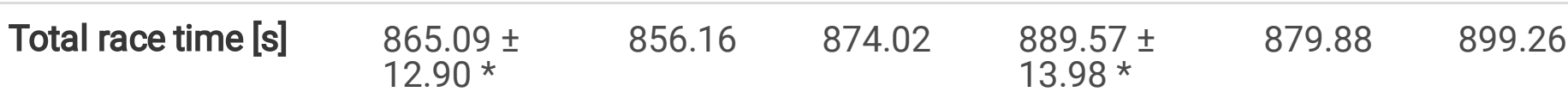

$\begin{array}{lllllll}\text { Total start section } & 3.77 \pm 0.16 & 3.66 & 3.88 & 3.77 \pm 0.17 & 3.65 & 3.89\end{array}$

time [s]

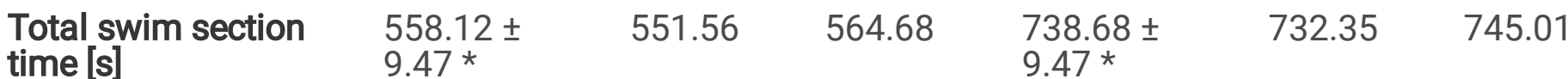

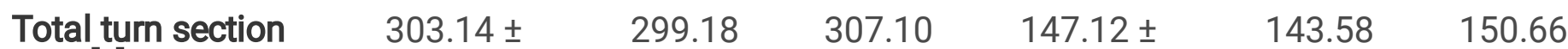

time [s]

5.71 *

$5.71 *$

3.88

$3.77 \pm 0.17 \quad 3.65$

3.89

Mean star
time $[s]$

Mean swim section

time [s]

$9.30 \pm 0.16 \quad 9.19$

9.41

$24.62 \pm$

0.33 *

24.39

24.85

Mean turn section

time [s]

$5.14 \pm 0.10 \quad 5.07$

5.21

$5.07 \pm 0.18$

4.95

5.19

Note:

* significant difference between short- and long-course races $(p<0.05)$ 
Table 2 - Pearson's correlation coefficient between final ranking and section rankings as well as total race time and section times.

\section{Short-course World championships}

$25 m$ pool length - Hangzhou 2018

$\begin{array}{llll}\begin{array}{l}\text { Final } \\ \text { ranking }\end{array} & \text { Section ranking } & \begin{array}{l}\text { Total race } \\ \text { time }\end{array} & \begin{array}{l}\text { Section time }[\mathbf{s}](+/ \text { - difference to race } \\ \text { winner) }\end{array}\end{array}$

\begin{tabular}{|c|c|c|c|c|c|c|c|}
\hline & & & \multirow[b]{2}{*}{ Turn } & & \\
\hline & Start & Swim & & & Start & Swim & Turn \\
\hline 1. place & 5. & 2. & 1. ${ }^{a}$ & 849.14 & 3.82 & 550.06 & $295.26^{a}$ \\
\hline 2. place & 8. & 1. & 4. ${ }^{b}$ & $\begin{array}{l}849.87(+ \\
0.73)\end{array}$ & $\begin{array}{l}4.08(+ \\
0.26)\end{array}$ & $\begin{array}{l}545.35(- \\
4.71)\end{array}$ & $\begin{array}{l}300.44(+ \\
5.18)^{b}\end{array}$ \\
\hline 3. place & 3. & 6. & 2. ${ }^{a}$ & $\begin{array}{l}859.39(+ \\
10.25)\end{array}$ & $\begin{array}{l}3.64(- \\
0.18)\end{array}$ & $\begin{array}{l}559.91(+ \\
9.85)\end{array}$ & $\begin{array}{l}295.84(+ \\
0.58)^{a}\end{array}$ \\
\hline 4. place & 4. & 5. & $3 .^{a}$ & $\begin{array}{l}863.44(+ \\
14.30)\end{array}$ & $\begin{array}{l}3.74(- \\
0.08)\end{array}$ & $\begin{array}{l}559.66(+ \\
9.60)\end{array}$ & $\begin{array}{l}300.04(+ \\
4,78)^{\text {a }}\end{array}$ \\
\hline 5. place & 6. & 4. & 6. ${ }^{b}$ & $\begin{array}{l}864.00(+ \\
14.86)\end{array}$ & $\begin{array}{l}3.86(+ \\
0.04)\end{array}$ & $\begin{array}{l}553.40(+ \\
3.34)\end{array}$ & $\begin{array}{l}306.74(+ \\
11.48)^{b}\end{array}$ \\
\hline 6. place & 1. & 3. & 8. ${ }^{b}$ & $\begin{array}{l}867.73(+ \\
18.59)\end{array}$ & $\begin{array}{l}3.56(+ \\
0.26)\end{array}$ & $\begin{array}{l}553.00(+ \\
2.94)\end{array}$ & $\begin{array}{l}310.74(+ \\
15.48)^{b}\end{array}$ \\
\hline 7. place & 7. & 7. & 5. & $\begin{array}{l}875.94(+ \\
26.80)\end{array}$ & $\begin{array}{l}3.88(+ \\
0.06)\end{array}$ & $\begin{array}{l}566.28(+ \\
16.22)\end{array}$ & $\begin{array}{l}305.78(+ \\
10.52)\end{array}$ \\
\hline 8. place & 2. & 8. & 7. & $\begin{array}{l}891.22(+ \\
42.08)\end{array}$ & $\begin{array}{l}3.60(- \\
0.22)\end{array}$ & $\begin{array}{l}577.32(+ \\
27,26)\end{array}$ & $\begin{array}{l}310.30(+ \\
15.04)\end{array}$ \\
\hline$r$-value & -0.36 & 0.74 & 0.81 & r-value & -0.52 & 0.91 & 0.76 \\
\hline$p$-value & 0.385 & 0.037 & 0.015 & $p$-value & 0.189 & 0.002 & 0.030 \\
\hline
\end{tabular}

\section{Long-course World championships}

$50 \mathrm{~m}$ pool length - Gwangju 2019

\section{Final Section ranking Total race Section time $[\mathbf{s}](+/$ - difference to race ranking time winner)}

Start Swim Turn

Start Swim Turn

$\begin{array}{llllllll}\text { 1. place } & 2 . & 2 . & \text { 1. }^{\mathrm{a}} & 876.54 & 3.62 & 731.06 & 141.86^{\mathrm{a}}\end{array}$

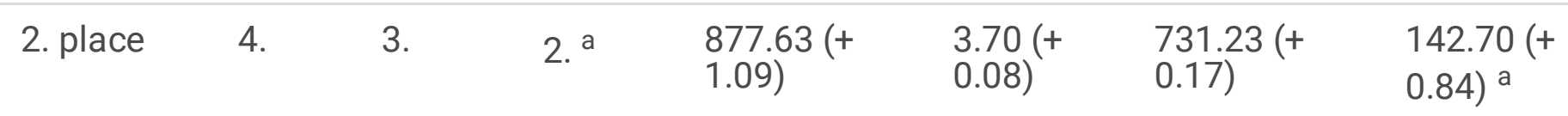

3. place $\quad 7 . \quad 1 . \quad$ 4. $^{\mathrm{b}} \quad 878.75(+$ 


\begin{tabular}{|c|c|c|c|c|c|c|c|}
\hline & & & & 2.21) & $0.34)$ & 1.69) & $3.56)^{b}$ \\
\hline 4. place & 3. & 4. & 5. & $\begin{array}{l}884.72(+ \\
8.18)\end{array}$ & $\begin{array}{l}3.68(+ \\
0.06)\end{array}$ & $\begin{array}{l}735.30(+ \\
4.24)\end{array}$ & $\begin{array}{l}145.74(+ \\
3,88)\end{array}$ \\
\hline 5. place & 1. & 5. & 3. & $\begin{array}{l}885.35(+ \\
8.81)\end{array}$ & $\begin{array}{l}3.50(- \\
0.12)\end{array}$ & $\begin{array}{l}738.75(+ \\
7.69)\end{array}$ & $\begin{array}{l}143.10(+ \\
1.24)\end{array}$ \\
\hline 6. place & 6. & 6. & 6. & $\begin{array}{l}892.05(+ \\
15.51)\end{array}$ & $\begin{array}{l}3.92(+ \\
0.30)\end{array}$ & $\begin{array}{l}740.27(+ \\
9.21)\end{array}$ & $\begin{array}{l}147.86(+ \\
6.00)\end{array}$ \\
\hline 7. place & 8. & 7. & 7. & $\begin{array}{l}901.04(+ \\
24.50)\end{array}$ & $\begin{array}{l}4.02 \\
(+0.40)\end{array}$ & $\begin{array}{l}744.22(+ \\
13,16)\end{array}$ & $\begin{array}{l}152.80(+ \\
10.96)\end{array}$ \\
\hline 8. place & 5. & 8. & 8. & $\begin{array}{l}920.47(+ \\
43.93)\end{array}$ & $\begin{array}{l}3.74(+ \\
0.12)\end{array}$ & $\begin{array}{l}759.25(+ \\
28.19)\end{array}$ & $\begin{array}{l}157.48(+ \\
15.62)\end{array}$ \\
\hline$r$-value & 0.43 & 0.93 & 0.93 & $r$-value & 0.24 & 0.99 & 0.96 \\
\hline$p$-value & 0.289 & $<0.001$ & $<0.001$ & $p$-value & 0.561 & $<0.001$ & $<0.001$ \\
\hline
\end{tabular}

\section{Note:}
${ }^{a}$ increased final ranking due to turn performance
${ }^{b}$ decreased final ranking due to turn performance

\section{Figures}


Short-course World championships

25 m pool length - Hangzhou 2018

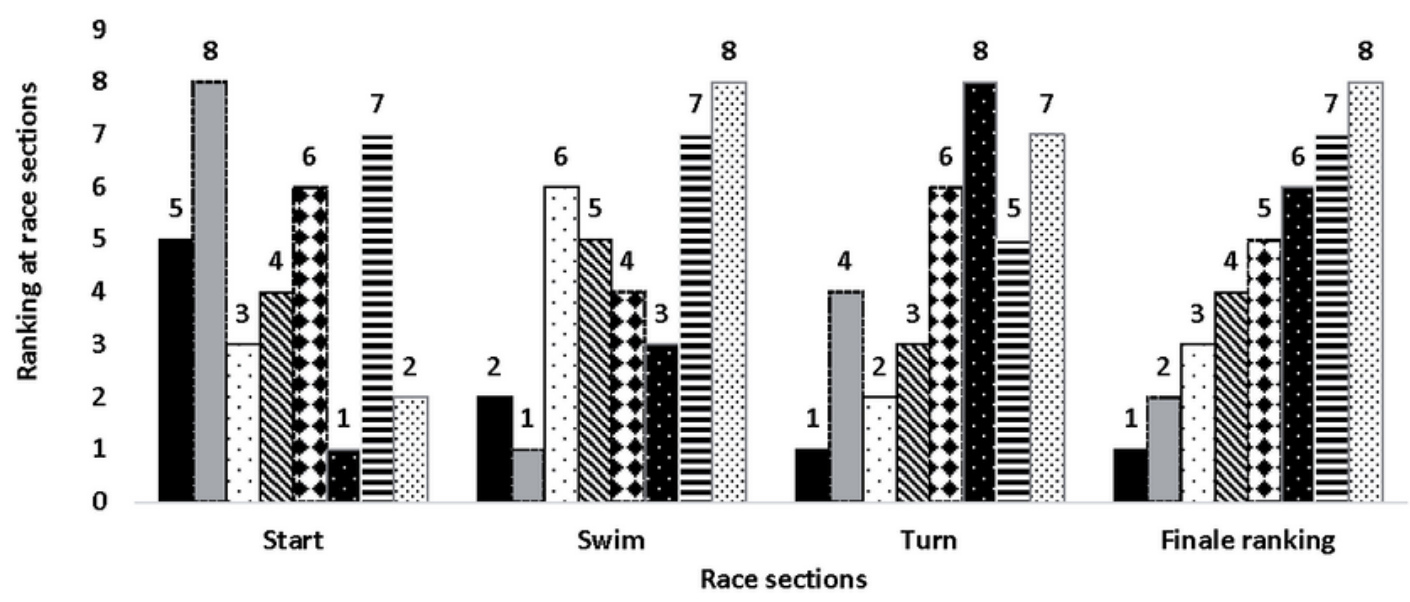

nswimmer placed 1st

[l] swimmer placed 2nd $\square$ swimmer placed 3rd

\$ swimmer placed 4th

S swimmer placed 5th

- swimmer placed 6th = swimmer placed 7th

Long-course World championships

$50 \mathrm{~m}$ pool length - Gwangju 2019

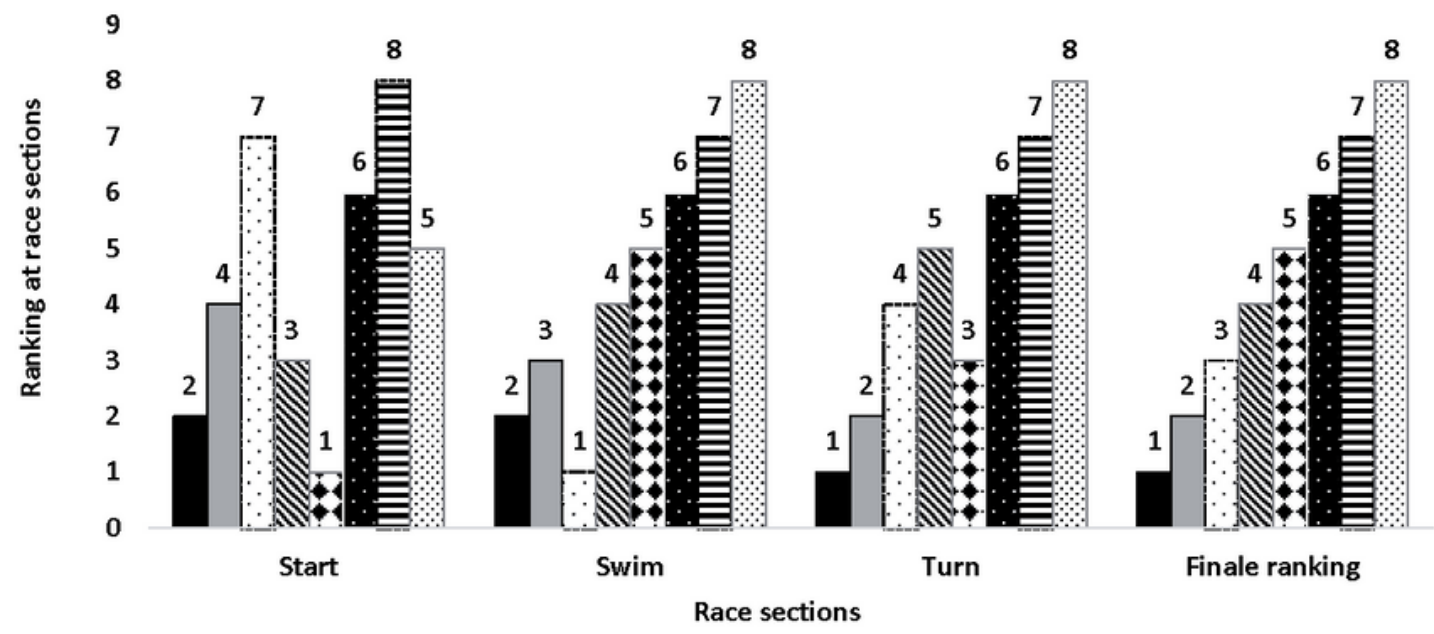

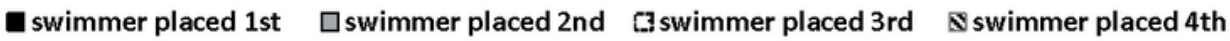

A swimmer placed 5th $\quad$ swimmer placed 6th Eswimmer placed 7th $\quad$ swimmer placed 8th

Figure 1

Individual ranking for start, swim, and turn section at the short-course and long-course World championships. 